\title{
Stromal characteristics may hold the key to mammographic density: the evidence to date
}

\author{
Alastair J. Ironside ${ }^{1}$ and $\mathrm{J}^{\text {. Louise } \text { Jones }^{1}}$ \\ ${ }^{1}$ Centre for Tumour Biology, Barts Cancer Institute, Queen Mary University of London, London, UK \\ Correspondence to: Alastair J. Ironside, email: alastair.ironside@qmul.ac.uk \\ Keywords: mammographic density, breast cancer, stroma, extracellular matrix, collagen \\ Received: July 23, 2015 \\ Accepted: January 02, 2016 \\ Published: January 13, 2016
}

\section{ABSTRACT}

\begin{abstract}
There is strong epidemiological data indicating a role for increased mammographic density (MD) in predisposing to breast cancer, however, the biological mechanisms underlying this phenomenon are less well understood. Recently, studies of human breast tissues have started to characterise the features of mammographically dense breasts, and a number of in-vitro and in-vivo studies have explored the potential mechanisms through which dense breast tissue may exert this tumourigenic risk. This article aims to review both the pathological and biological evidence implicating a key role for the breast stromal compartment in MD, how this may be modified and the clinical significance of these findings. The epidemiological context will be briefly discussed but will not be covered in detail.
\end{abstract}

\section{EPIDEMIOLOGY OF MAMMOGRAPHIC DENSITY}

Mammographic density (MD) refers to the proportion of a mammogram occupied by radiologically dense fibroglandular tissue and is a major independent risk factor for breast cancer. A comprehensive meta-analysis of 14,000 cases observed that women with $>75 \%$ breast density had 4-6 times the risk of developing breast cancer compared to women with breasts of the lowest $25 \%$ density [1]. The relative risk imparted by high MD is greater than family history or menstrual and reproductive risk factors, only age and BRCA mutation status are associated with a higher relative risk [2]. However, given the high frequency of breast density in the general population, the attributable risk is substantial and it is estimated that approximately one third of breast cancers could be explained by density in more than $50 \%$ of the breast [3]. High MD is also associated with increased local recurrence and risk of second primary breast cancer $[4,5]$.

MD appears to be highly heritable; studies of twins have attributed up to $65 \%$ of the variation in MD to genetic factors $[6,7]$ with the remaining $35 \%$ being modifiable.

The majority of studies investigating the genetic contribution to MD have focused on investigating the single nucleotide polymorphisms (SNPs) associated with increased breast cancer risk and their relationship with MD. So far SNPs in the region of ESR1, CCDC170,
EBF1, LSP1, MIR1972-2:FTO, RAD51L1，ZNF365, MKL1, TNRC9/TOX 3, NTN4, NEK10, TAB2 and loci at 2 p24.1 and $12 \mathrm{q} 24$ [8-14] have all been identified as having a significant association with MD. In addition, a recent meta-analysis of 10,727 women found that $18 \%$ of breast cancer susceptibility variants were associated with at least one MD measure [14]. Despite this, these SNPS are thought to account for only a small percentage of the variance in breast density with the remainder attributed to genes that are currently unknown [9]. Studies investigating more established genetic mutations known to confer a strong risk for breast cancer have focused on BRCA1 and BRCA2, and have demonstrated no significant association with MD $[15,16]$. To date, no studies have investigated other established genetic risk factors such as phosphatase and tensin homolog (PTEN), tumour protein 53 (TP53), E-Cadherin (CDH1) or serine/threonine kinase 11 (STK11) for association with MD. Therefore much of the remaining genetic contribution to MD remains to be elucidated.

\section{MODIFIERS OF MAMMOGRAPHIC DENSITY}

A key feature of MD compared to other established risk factors for breast cancer is that it is dynamic and modifiable. This modifiability offers significant 
therapeutic potential in the form of cancer prevention strategies targeted to reduce breast density. MD typically decreases with age, whereas breast cancer incidence conversely increases with advancing age. The Pike model attempts to resolve this apparent paradox by suggesting that cumulative lifetime exposure of the breast to dense tissue and associated growth factors and hormones, also referred to as 'breast tissue ageing', confers the age-related risk of developing breast cancer [17].

This is reflected in the apparent hormonally responsive nature of $\mathrm{MD}$; women with known risk factors for breast cancer related to prolonged oestrogen exposure, such as late first pregnancy and early menarche, show a higher degree of MD. In addition, the use of combined hormone replacement therapy also increases MD [18, 19]. Conversely parous women have a lower degree of MD (approximately a 10\% reduction per live birth [20]) and there is a significant reduction in MD following the menopause [21, 22]. An important confounding factor is that MD is also negatively associated with body mass index (BMI), an independent risk factor for breast cancer [20,23]. High BMI reduces percentage density by increasing the non-dense portion of the breast and has also been associated with reduced absolute density in some studies $[24,25]$, however this is not a consistent finding [26, 27]. Failure to correct for BMI may lead to a significant underestimation of risk [23].

Given that MD appears to be hormonally responsive, one might expect high MD to predispose to the development of oestrogen receptor (ER) positive tumours, however to date studies have reported inconsistent findings. McCormack and dos Santos Silva have recently performed a systematic meta-analysis incorporating over 24,000 cases, finding a similar magnitude of association with ER+ and ER- tumours and no difference in the association with human epidermal growth factor receptor 2 (HER2) status [28].

Tamoxifen is a selective oestrogen receptor modulator, demonstrated in the IBIS- 1 study to reduce $\mathrm{MD}$ and breast cancer risk [29]. A further nested case control study within the IBIS 1 cohort revealed that, in those women taking tamoxifen, those who showed a > $10 \%$ reduction in MD had a $63 \%$ lower risk of developing breast cancer [30]. Furthermore, those women who showed a poor response to tamoxifen treatment $(<10 \%$ reduction in MD) showed no associated risk reduction. Thus the protective effect of tamoxifen appears associated with a reduction in MD. This has been further highlighted in a recent retrospective study of breast cancer patients who received adjuvant tamoxifen for 15 years [31]. A 20\% relative reduction in $\mathrm{MD}$ was reported for women who took tamoxifen and this reduction was associated with a $50 \%$ risk reduction in breast cancer mortality [31].

Presently the mechanisms conferring susceptibility to the protective effect of tamoxifen treatment remain unknown, however, an association of cytochrome P450
2D6 (CYP2D6) metabolizer status with MD change in response to tamoxifen has recently been reported [32].

In an animal model of breast cancer, tamoxifen treatment initiated remodelling of the mammary stroma to a tumour inhibitory phenotype with lower levels of fibronectin and reduced extra-cellular matrix (ECM) turnover [33]. Furthermore a recent study utilising a xenograft model of high MD human tissue maintained in murine biochambers showed that tamoxifen treatment resulted in a reduction in radiographic tissue density characterised histopathologically by a decrease in stromal tissue and increase in adipose tissue [34]. The evidence from these studies suggest that tamoxifen may modulate density and breast cancer risk by modifying the stromal microenvironment of the breast.

\section{PATHOLOGICAL CORRELATE OF MAMMOGRAPHIC DENSITY}

MD reflects variations in the tissue composition of the breast and is positively associated with collagen, epithelial and stromal cells and negatively associated with fat [35]. Stroma is the major tissue component of the breast and is composed of stromal cells (fibroblasts, endothelial cells, immune cells and adipocytes) and ECM proteins, the most abundant of which is collagen I. A number of studies have indicated that mammographic density corresponds more to alterations in stromal composition rather than epithelial changes [36-39].

A comprehensive study by $\mathrm{Li}$ and colleagues examined histological features of breast tissue obtained at forensic autopsy [35]. They found that the area of stromal collagen was most strongly associated with percentage density and accounted for $29 \%$ of the variation in percentage density whereas nuclear area and glandular area accounted for between 4 and $7 \%$ of the variation [35]. Similarly, Pang et al have recently reported a significant association of increasing MD with increased proportion of fibrous stroma [40]. In addition, Huo and colleagues have reported more organised stromal collagen present in high MD breast tissue compared to low MD tissue [41]. Thus there are potentially both quantitative and qualitative aspects to the stromal differences in high MD, both of which need to be considered when trying to dissect underlying biological mechanisms.

It has been hypothesised that MD may represent the influence of local oestrogen production on the breast [42]. However, systemic levels of oestrogen have so far only shown an inverse or no association with MD [43]. Serum levels of prolactin and insulin-like growth factor 1 (IGF-1) have been associated with MD in a number of studies [44, 45]. In addition, dense breast tissue has been associated with higher levels of tissue inhibitor of metalloproteases 3 , higher immunohistochemical expression of IGF-1 [46] and with stromal proteoglycans lumican and decorin [36]. Furthermore, genetic polymorphisms in several 
components of the insulin-like growth factor (IGF) pathway also show an association with increased MD [47].

Despite the association of stromal content and high MD breast tissue, there is no standardised approach to measuring MD in histological sections. This, combined with the fact that MD is often heterogeneous in nature throughout the breast, poses a significant challenge to the planning of translational studies using human tissue.

\section{BIOLOGICAL MECHANISMS CONTRIBUTING TO THE DENSITY- ASSOCIATED RISK}

Whilst there is a strong clinical correlation, MD has not yet been causally linked to tumour formation and there have been a limited number of studies investigating the biological pathways mediating MD. Given that the stroma forms the major constituent component of dense breast tissue, the pathways contributing to the density-associated breast cancer risk are likely to involve the stromal cells, ECM proteins, and their interaction with the epithelial component.

The stromal microenvironment is known to have an important role in the progression of established invasive breast cancer [48], acting via multiple diverse mechanisms including the influence of growth factors secreted by cancer associated fibroblasts and remodelling of the ECM $[48,49]$. In addition, ECM gene expression levels are also associated with breast cancer prognosis [50], response to neo-adjuvant chemotherapy [51] and endocrine therapy [52]. Similar stromal mechanisms may also have a role in promoting tumourigenesis in breast tissue of high MD; the evidence for this is reviewed below.

\section{Paracrine factors}

It has been hypothesised that in areas of high MD, abundant stromal fibroblasts may aberrantly secrete growth factors and hormones/cytokines that stimulate epithelial cell proliferation [46, 53]. One study has suggested that local oestrogen production in the breast may be responsible for determining density [42]. Local oestrogen is synthesized from androgens in the breast by aromatase enzyme activity. Studies from Vachon et al and Huo et al have both reported increased aromatase immunoreactivity in the stromal cells of mammographically dense regions of the breast compared to non-dense regions [41, 42]. Increased stromal aromatase activity could result in sufficient local oestrogen production to stimulate epithelial cell proliferation and drive tumourigenesis. These findings are supported by in-vitro work from another group who have observed that cell density, shape and ECM proteins are capable of inducing stromal aromatase expression [54], thus providing a potential mechanistic link. This study also highlighted a role for I $\mathrm{B}$-kinase- $\beta$ (IKK $\beta$ ) as a key messenger in mediating this response. Figure 1a summarises the potential contribution of paracrine and mechanical factors to the induction of stromal cell aromatase activity.

\section{Collagen density, force and ECM stiffness}

It has been suggested that increased collagen production by stromal fibroblasts contributes to a stiffer ECM. The inability of normal breast epithelium to contract stiff matrix causes a tensional imbalance, reflected by altered signalling pathways that have the potential to

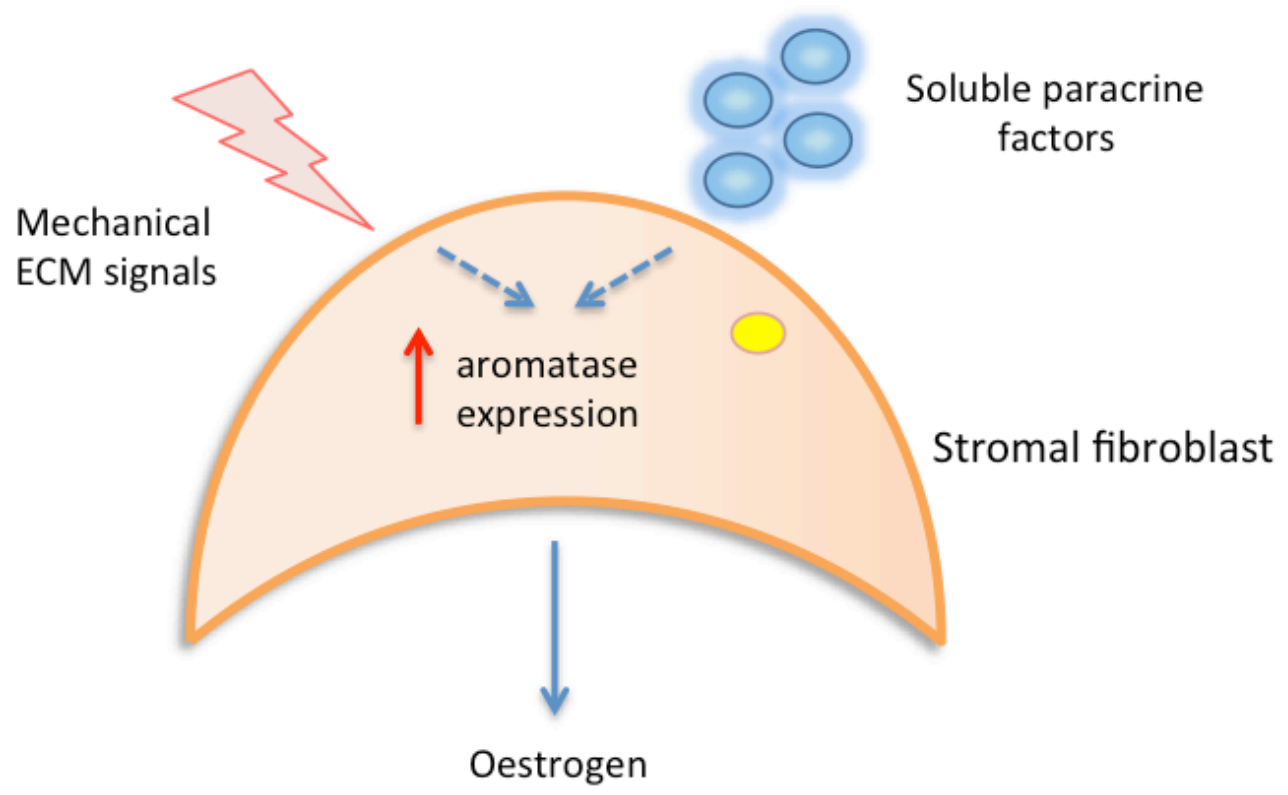

Figure 1a: Local paracrine and mechanical signals may contribute to increased stromal aromatase expression, resulting in increased local oestrogen production and epithelial cell proliferation. 
induce epithelial cell proliferation [55].

Patricia Keely and colleagues developed a bitransgenic mouse to model high breast density, utilising the Colla $1^{\text {tmJae }}$ transgene which reduces collagen proteolysis, and examined the propensity for tumour formation with increased mammary collagen. They observed that higher stromal collagen density in mouse mammary tissue resulted in a threefold increase in tumour number and that the tumours which developed displayed a more invasive phenotype with greater local invasion and metastasis. The authors propose a functional link between increased stromal collagen density and breast cancer initiation and progression [56].

Two possible mechanisms are suggested by which increased collagen density might promote tumour development. The first is a direct effect of increased matrix stiffness, resulting in a higher mechanical force and resistance to contractility on the epithelial cells. These forces might alter focal adhesion and Rho GTPase (Rho) signalling, resulting in increased proliferation [56]. The second proposed mechanism is more indirect and suggests that collagen density modulates the behaviour of mammary fibroblasts, resulting in altered secretion of soluble growth factors and chemokines such as transforming growth factor beta (TGF- $\beta$ ), epidermal growth factor (EGF) and IGF, which in turn influence epithelial cell behaviour [56], as summarised in Figure 1b.

Further work by this group examined whether collagen density alone, in the absence of fibroblasts, could alter mammary epithelial cell behaviour in 3D culture models. Supporting this hypothesis, greater collagen density alone increased matrix stiffness and promoted epithelial cell proliferation and invasion [57]. They showed that mammary epithelial cells formed clustered 3D matrix-adhesions containing activated focal adhesion kinase (FAK) in response to matrices of high stiffness. FAK, Rho and extracellular signal-related kinase (ERK) were all found to be necessary for successful mechanotransduction of mammary epithelial cells, and inhibition of ERK or the Rho/Rho-associated protein kinase (ROCK) pathway reverted the invasive phenotype promoted by high density matrices [57].

The authors propose that continued mechanical stimulation from a dense stromal matrix results in sustained activation of FAK-Rho signalling which, in turn, up-regulates other pathways such as Ras- Mitogen activated protein kinase (MAPK). ERK acts as a crucial bottleneck, regulating the response and inducing transcription of proliferation associated genes.

Soon et al examined the effect of high density collagen matrices on mammary epithelial cell behaviour. They found that high density matrices up-regulated the expression and activity of Rho-associated coiled-coilcontaining protein kinase 1 (ROCK 1) via inhibition of notch homolog 1 (NOTCH1) [58]. ROCK- 1 is proposed to have a key role in cell contractility and facilitating epithelial cell migration in conjunction with matrix-metalloproteinase (MMP) proteolytic activity, thus providing an alternative mechanism for density modulation of cell behaviour.

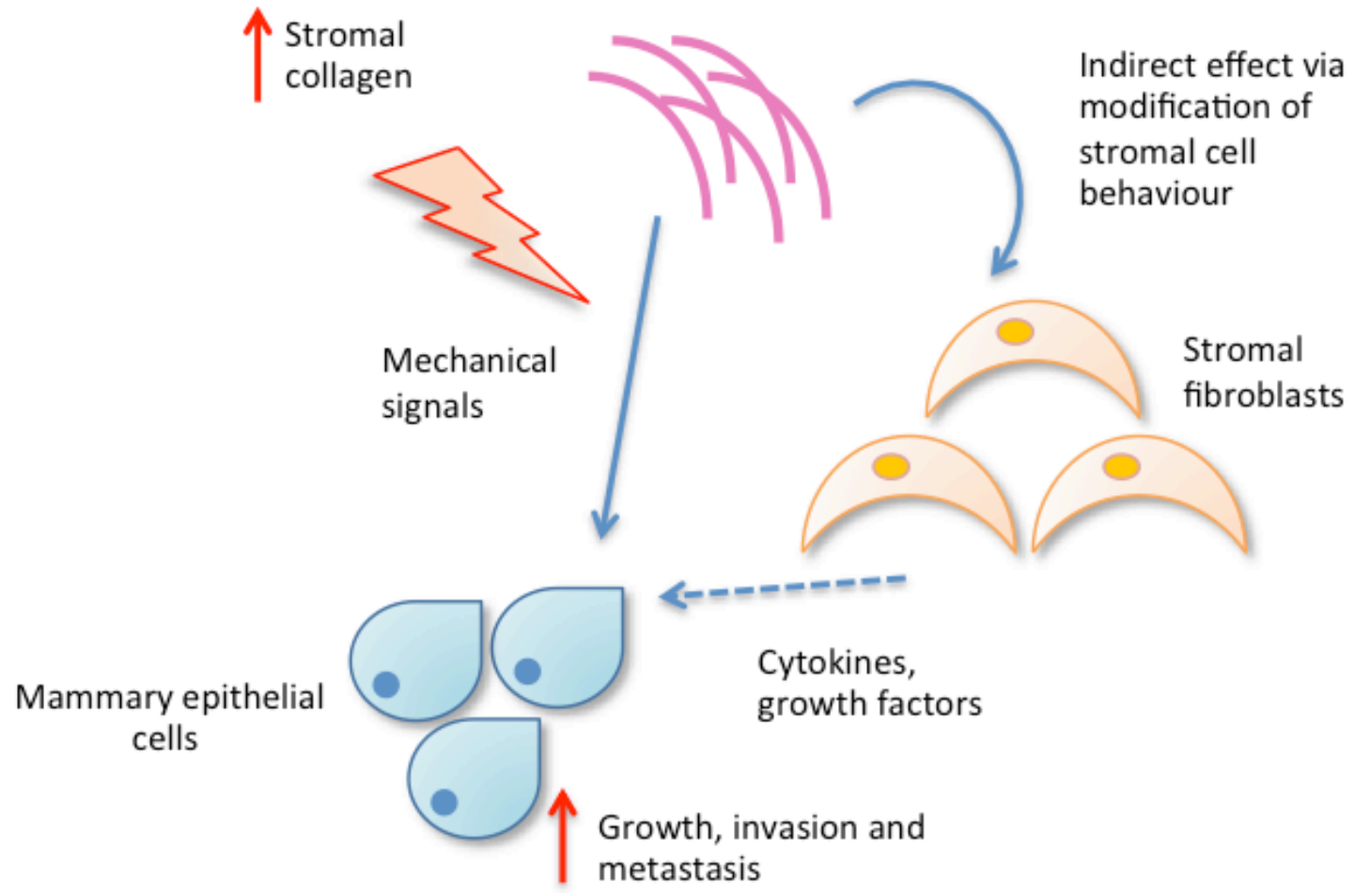

Figure 1b: Increased collagen density may influence mammary epithelial cell behaviour directly via mechanistic signals or indirectly via modifying stromal cell behaviour. 
As well as collagen density, the significance of collagen fibre alignment within the ECM in facilitating mammary tumour cell invasion has also been investigated by the Keely group [59]. Collagen changes at the tumour/ stroma boundary termed 'Tumour associated collagen signatures' (TACS) have been classified and used as markers of malignant progression. TACS-3, where the collagen fibers are orientated perpendicular to the tumour boundary, has been shown to correspond to sites of focal invasion in mouse models $[56,59]$ and in an analysis of human tissue samples is also associated with poor disease-specific and disease-free survival [60]. The precise biological mechanisms mediating alignment of the ECM remain unclear though it has been suggested that syndecan signalling, cyclooxygenase-2 (COX-2) signalling, stromal immune cells and other glycoproteins such as neutrophil gelatinase-associated lipocalin (NGAL) may play a role [55]. These data emphasise the importance of assessing both qualitative and quantitative elements of the stroma when considering the impact of mammographic density.

\section{Collagen cross-linking, integrin signalling and ECM stiffness}

Weaver and colleagues have investigated how collagen cross-linking mediated by lysyl oxidase (LOX), a family of ECM cross-linking enzymes, can influence mammary epithelial cell behaviour. They used the MMTV-Neu mouse model of breast cancer to show that fibroblasts overexpressing LOX form a stiffer mammary fat pad and promote the growth and invasion of premalignant mammary epithelial cells. Similarly, inhibition of LOX resulted in a less stiff matrix and reduction in tumourigenesis [61]. LOX-mediated collagen cross-linking resulted in a stiff matrix characterised by increased focal adhesions, integrin clustering and subsequent increase in integrin signalling, increased FAK activity and enhanced phosphotinositide 3-kinase (PI3-K) signalling. PI3-K signalling has been suggested to promote invasion of mammary epithelial cells in-vitro and tumourigenesis in-vivo [62]. Thus it is proposed that LOX may have a pivotal role in modulating breast tumour progression by stiffening the ECM and initiating integrin mediated mechanotransduction of mammary epithelial cells. In keeping with these findings, LOX expression is also elevated in many cancers [63], has been associated with prognosis [64] and is proposed to have a key role in facilitating tumour metastasis [65].

More recent work by the same group, focusing on the molecular determinants of mammary epithelial cell mechanotransduction, has highlighted a crucial role for the focal adhesion component vinculin in translating the mechanical cues from a stiff ECM into tumour promoting intracellular signalling pathways [66]. It is suggested that a stiff ECM drives integrin binding and activation, forming focal adhesions. At the focal adhesion, vinculin is activated and binds talin and actin forming a stable talinvinculin-actin complex. The stabilisation of this complex facilitates PI3-K conversion of phosphatidylinositol 4,5-bisphosphate (PIP2) to phosphatidylinositol $(3,4,5)$-trisphosphate (PIP3), phosphorylation of FAK and protein kinase $\mathrm{B}$ (AKT) and upregulation of protumourigenic signalling pathways [66]. Thus, common mechanisms for mammographic density signalling, centering around focal adhesions and the cytoskeleton, are

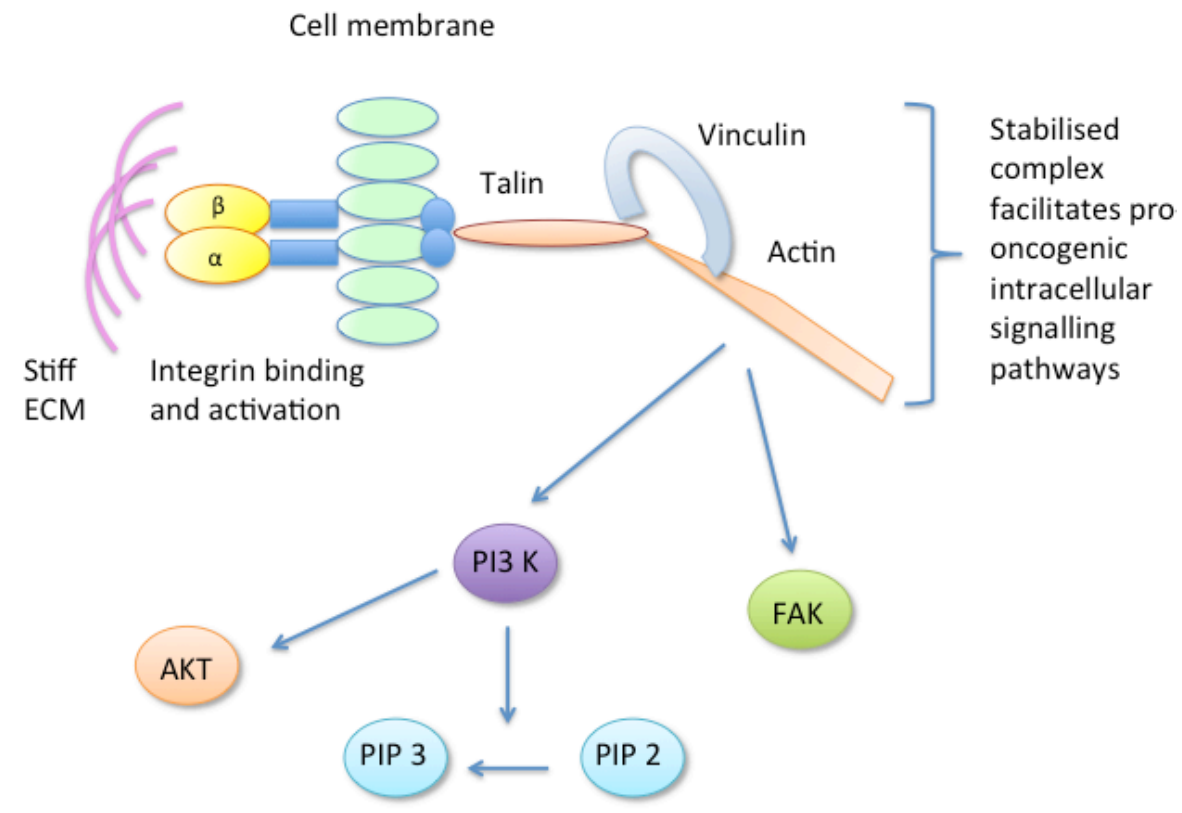

Figure 2: The focal adhesion component vinculin is activated in response to stiff ECM, forming a stable talin-vinculinactin complex which promotes pro-oncogenic signalling pathways. 
becoming apparent, as summarised in Figure 2.

The Weaver group have also recently reported that changes in ECM stiffness can modulate micro RNA expression [67]. They demonstrated that increased matrix stiffness in both human and mouse mammary tissue induces expression of micro RNA-18a (miR-18a) via integrin-dependent activation of $\beta$-catenin and MYC. miR18a subsequently interacts and inhibits expression of the tumour suppressor gene PTEN, which itself is a negative regulator of PI3-K activity - previously demonstrated as a key pathway promoting mammary epithelial cell malignant progression [61]. miR-18a was also noted to indirectly inhibit PTEN expression via decreasing levels of homeobox A9 (HOXA9) (Figure 3). In this study miR18a levels were able to distinguish luminal A from luminal B tumours and high miR-18a expression was predictive of poor outcome in tissue biopsies of patients with luminal breast cancers, suggesting that this pathway could be utilised clinically. Whether this could be used to monitor patient response to chemopreventive measures remains to be determined.

\section{Reduced expression of CD36}

One of the key features of high mammographic density is the change in balance of adipose tissue to fibrous stroma, and it might be anticipated that factors determining adipose differentiation may be altered. A recent study from Tlsty and colleagues has suggested a critical role for the transmembrane receptor CD36 in mediating MD by controlling two key density-determining factors: stromal adipocyte content and ECM accumulation [68]. Gene expression profiling was used to determine differentially expressed genes in fibroblasts from high and low density disease-free breast tissue and cancer associated fibroblasts. CD36 expression was repressed in a range of stromal cell types (fibroblasts, adipocytes, endothelial cells) in both tissues of high MD and in tumour stroma. Loss of stromal CD36 expression in-vitro and in-vivo resulted in less fat accumulation and greater ECM accumulation, a phenotype shared by tissues of high MD and desmoplastic tumour stroma [68]. They have suggested that reduced CD36 expression across multiple stromal cell types results in a complex, coordinated set of signalling pathways which increases the risk of tumour development via a variety of mechanisms including adipocyte differentiation, angiogenesis, cell-ECM interaction and immune signalling. In addition, clinically more aggressive tumours were associated with a greater degree of CD36 repression [68]. These findings highlight the potential importance of CD36 as a targetable stromal biomarker of MD associated risk in the cancer prevention setting.

Further work by this group has demonstrated that epithelial cells in high MD tissue show more DNA damage signalling, shorter telomeres and increased activin A secretion compared to low density tissue [69]. In addition epithelial expression of activin A and telomere dysfunction were capable of reducing CD36 expression in the surrounding stromal fibroblasts, suggesting a potential pathway by which high MD tissue might arise. Whether the initiating DNA damage event occurs in the epithelial or stromal compartment of the breast remains to be elucidated, but these studies highlight the dynamic interaction between stromal and epithelial compartments.

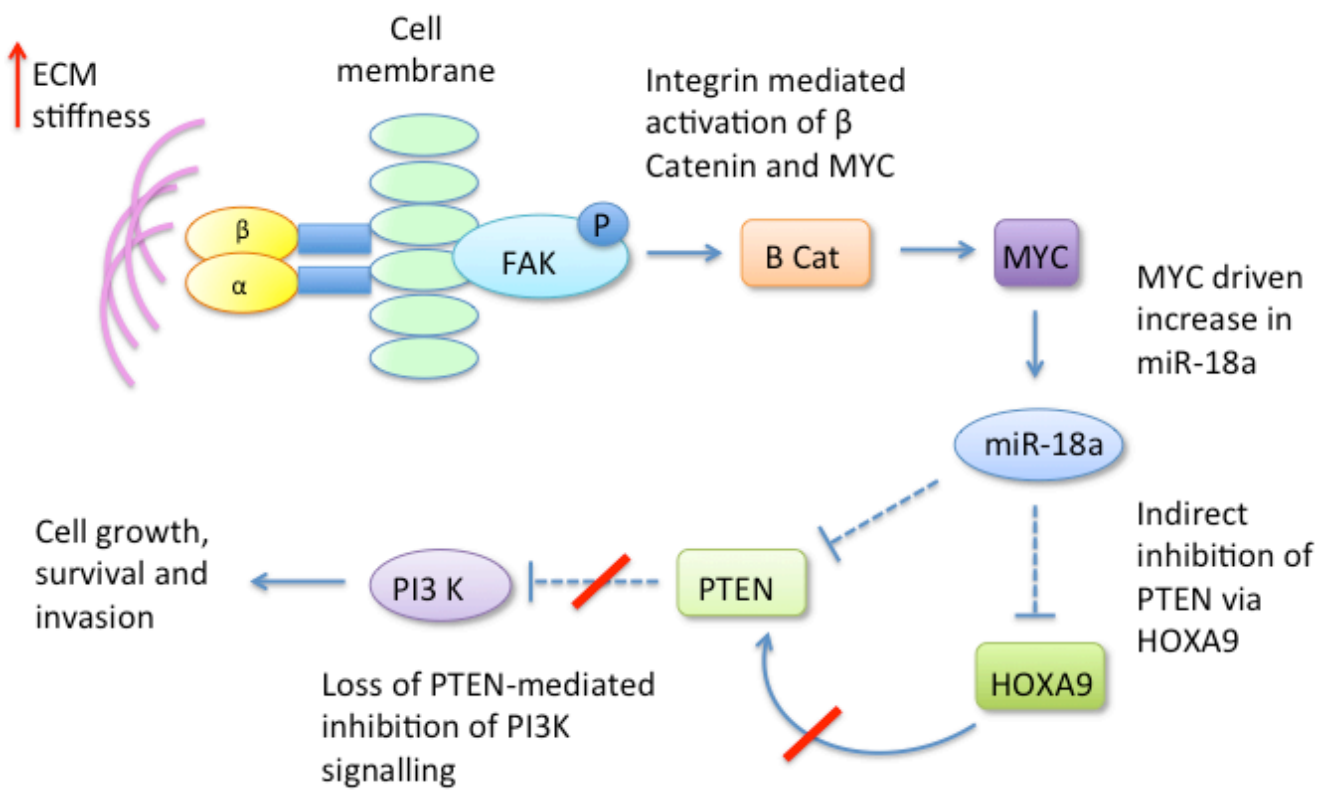

Figure 3: Dense ECM induces expression of micro RNA 18a via activation of MYC and beta catenin. miR-18a inhibits PTEN both directly and indirectly via HOXA9, resulting in upregulation of PI3-K signalling. 


\section{JNK1 stress signalling and myofibroblast phenotype}

Further interrogating gene expression array data from low- and high-density fibroblasts, Lisanti et al focused on genes that were transcriptionally up-regulated by at least 1.5 fold in high compared to low density fibroblasts [70]. They performed gene-set enrichment analysis and found that high density fibroblasts demonstrated up-regulation of several cellular processes including stress signalling, stemness, angiogenesis, inflammation and fibrosis. These processes are similar to those observed in the wound healing response and could potentially mediate a pro-inflammatory and pro-fibrotic microenvironment, with high density fibroblasts sharing similar characteristics to activated myofibroblasts.

In addition, when the high density fibroblast gene signature was compared to the profile of tumour stroma, c-Jun N-terminal kinase 1 (JNK-1) stress signalling emerged as the most significant biological process shared between the two data sets [70]. The authors postulate that the stromal JNK-1 activation occurs via stressors in the microenvironment such as reactive oxygen species,
TGF- $\beta$ and fibroblast growth factor (FGF) signalling. The activated JNK-1 stress signalling mediates the onset of a 'myofibroblast' phenotype characterised by ongoing inflammation and fibrosis, resulting in pro-tumourigenic, high density stroma [70]. The authors also highlight a potential role for JNK-1 inhibitors as a cancer prevention strategy by inhibiting the development of the high density fibroblast phenotype.

Whether such markers of an activated stroma could be used to measure patient risk and as indicators of response to treatment strategies is an intriguing possibility.

\section{Mitogenesis, mutagenesis and the 'Inactive' stromal microenvironment gene signature}

Martin and Boyd have proposed that the combined effects of cell proliferation (mitogenesis) and genetic damage to proliferating cells by mutagens (mutagenesis) may account for the increased risk of breast cancer with high MD [71]; a hypothesis similar to the concept of 'breast tissue ageing' proposed by Pike [17]. The Martin and Boyd model has been further adapted by Sun and colleagues, who examined stromal gene expression

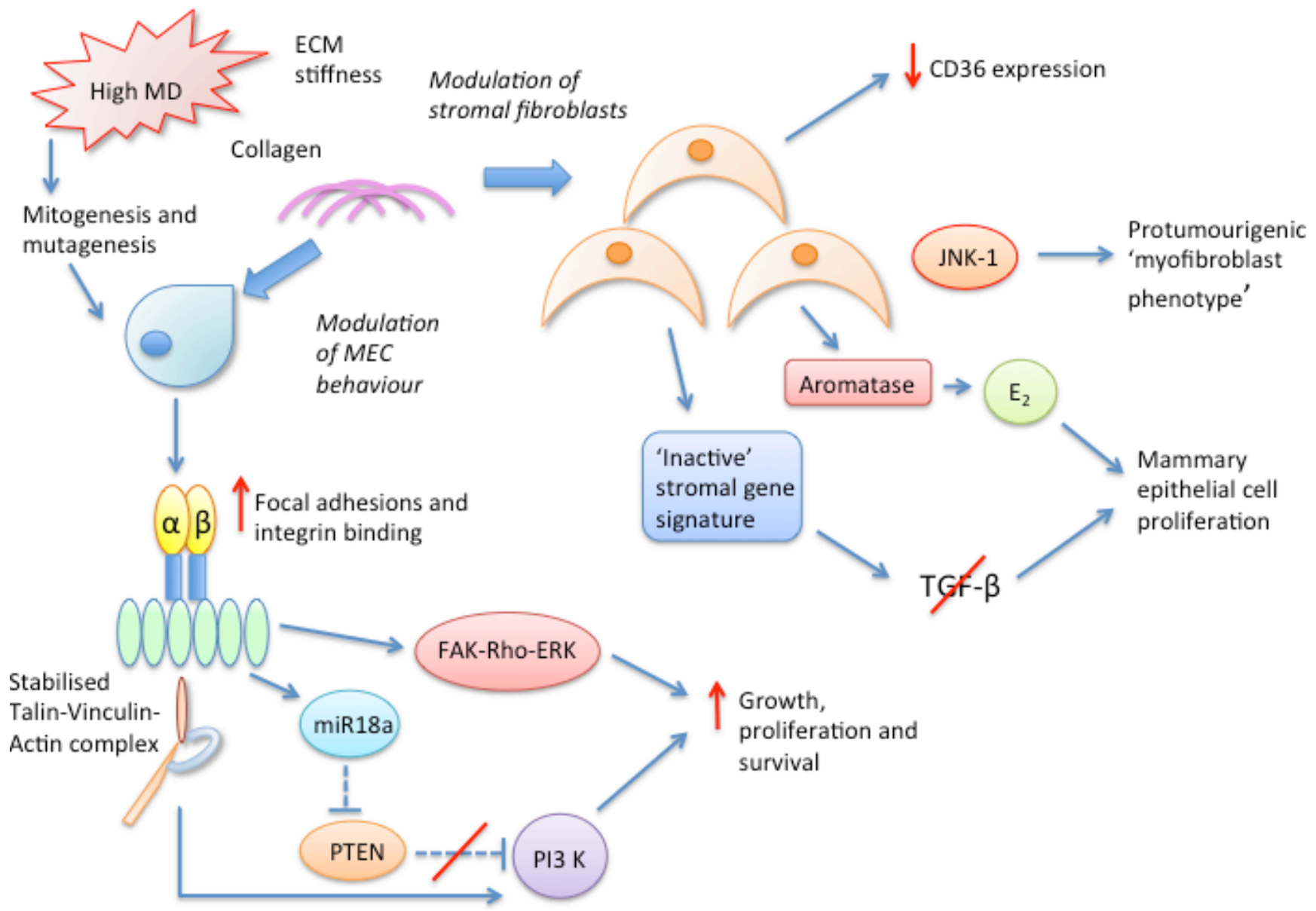

Figure 4: Potential stromal molecular pathways mediating the density associated cancer risk conferred by high MD breast tissue. 
signatures from non-neoplastic breast tissue adjacent to invasive carcinoma in a series of breast cancer patients. They found that high MD was particularly associated with an 'Inactive' stromal microenvironment signature [39]. This inactive subtype was associated with increased stromal composition, higher expression of cellular adhesion genes, increased oestrogen response gene expression and reduced TGF- $\beta$ signalling. Interestingly, the observation of reduced TGF- $\beta$ signalling in high MD stroma is somewhat contradictory to the model proposed by Lisanti et al, discussed in the previous section. A possible explanation for this discrepancy is that the morphologically normal tissue adjacent to invasive carcinoma sampled in the study by Sun et al may be displaying aberrant gene expression, due to the proximity to the tumour. Therefore, it may not be representative of truly non-neoplastic breast tissue.

These data further emphasize the importance of stromal biology in mediating MD. The revised Martin and Boyd model incorporates and highlights the role of the stromal microenvironment in breast tumourigenesis.

Reduced TGF- $\beta$ signalling in dense breast tissue has also been observed by Yang and colleagues who compared gene expression in high and low density non-tumour breast tissue taken $5 \mathrm{~cm}$ away from invasive carcinoma [72]. A number of genes implicated in TGF- $\beta$ signalling showed decreased expression in dense tissue (TGFBR2, SOS, SMAD3, CD44 and TNFRSF11B). Immunohistochemical analysis of the same tissues showed higher stromal expression of COX-2 and proliferation marker Ki67 [72]. Inhibition of TGF- $\beta$ by COX has previously been reported in other organ systems [73] and loss of TGF- $\beta$ ligand-mediated inhibition of mammary epithelial cell proliferation is proposed as a potential mechanism for density-associated breast cancer risk. The authors also suggest a potential role for COX-2 inhibitors as a breast cancer prevention strategy for high risk individuals. This is somewhat counter-intuitive, given the established pro-fibrogenic role of TGF- $\beta$. Furthermore, of note, the increased stromal Ki67 expression observed in this study is inconsistent with data from other groups who have reported no association of Ki67 with $\mathrm{MD}[41,74,75]$. A recent study by Chew and colleagues has also reported increased COX-2 expression in the stromal and (to a lower degree of significance) epithelial cells of high MD breast tissue in both human samples and a xenograft model of MD [76].

A summary of our current understanding of the complex stromal biological pathways conferring MDassociated breast cancer risk is displayed in Figure 4 below.

Despite the progress made in these preclinical studies towards identifying potential stromal markers and signalling pathways contributing to breast density, this has not readily translated into clinically relevant markers or targets. Further clinically applicable approaches are needed to identify the key stromal molecules driving density-associated risk in humans.

\section{CLINICAL RELEVANCE}

The influence of MD on breast cancer risk has a number of important clinical implications, particularly with regard to identification of high risk individuals, screening and prevention. Four studies have investigated whether including a measure of MD improves risk estimation compared to standard risk models [77-80]. All of these studies found a small but consistent improvement in risk estimation with the addition of MD measures, highlighting the potential clinical power of MD to accurately identify populations at increased risk of breast cancer.

Screening at more frequent intervals with more than one imaging modality may be appropriate for women with dense breasts due to their increased risk of developing cancer and their increased risk of tumour 'masking'. A recent analysis of personalised mammographic screening according to MD, age, family history and history of breast biopsy was found to be cost effective [81].

It has been postulated that change in MD could be used as a marker in clinical trials evaluating breast cancer prevention strategies [82]. This could reduce the need for long observation periods currently required to evaluate the likelihood of developing breast cancer following an intervention. The results from a recent retrospective study by Li et al has suggested that reduction in MD can be used as a prognostic marker of response to adjuvant tamoxifen treatment [31].

MD is more strongly associated with breast cancer risk than other variables such as family history and reproductive factors. Therefore, knowledge of an individual's mammographic density and in particular, their expression levels of genes coding for ECM proteins and other stromal biomarkers, may allow individual risk prediction for breast cancer. MD also offers the advantage over other breast cancer risk factors of being modifiable, which provides exciting potential for therapeutic intervention to reduce both MD and breast cancer risk.

Targeting components of the microenvironment is already an established strategy in the adjuvant treatment setting for a number of different tumour types [83, 84]. The most advanced of these strategies are agents targeting vascular endothelial growth factor (VEGF) signalling in the tumour vasculature with a number agents now licenced for use in several metastatic cancers in combination with cytotoxic therapies [84, 85]. Beyond VEGF there are several other anti-angiogenic agents in preclinical trials targeted against platelet derived growth factor (PDGF) and FGF signalling pathways $[86,87]$.

Components of tumour-associated inflammation are also a focus of new agents targeted against the microenvironment. An interleukin 6 (IL-6) neutralising 
antibody is currently undergoing evaluation in clinical trials [88], and neutralising antibodies against human chemokines have shown promising results in preclinical models of prostate and breast cancer [89]. Disrupting tumour-stroma crosstalk via integrin inhibition is also the subject of clinical trials with agents showing limited antitumour efficacy at present $[90,91]$. Specifically targeting tumour-associated fibroblasts, utilising their expression of fibroblast activation protein $\alpha$ (FAP), remains at the preclinical stage of development. Such strategies involve; the development of anti-FAP antibodies conjugated to cytotoxic drugs [92], utilising the enzymatic activity of FAP to activate pro-drugs in the vicinity of the tumour [93], and vaccines targeted against FAP [94].

Harnessing similar approaches in the preventive setting to target the stromal molecules and pathways mediating MD could provide an effective cancer prevention strategy. Thus, further work to dissect the complex biological pathways mediating MD is urgently needed to identify novel, clinically relevant, biomarkers driving the density-associated risk.

\section{CONFLICTS OF INTERESTS}

The authors declare they have no conflict of interest.

\section{REFERENCES}

1. McCormack VA and dos Santos Silva I. Breast density and parenchymal patterns as markers of breast cancer: A meta analysis. Cancer, Epidemiology, Biomarkers and Prevention. 2006; 15:1159-1169.

2. Veronesi U, Boyle P, Goldhirsch A, Orecchia R and Viale G. Breast Cancer. Lancet. 2005; 365(9472):1727-1741.

3. Boyd NF, Rommens JM, Vogt K, Lee V, Hopper, Yaffe MY and Paterson AD. Mammographic breast density as an intermediate phenotype for breast cancer. Lancet Oncology. 2005; 6:798-808.

4. Cil T, Fishell E, Hanna W, Sun P, Rawlinson E, Narod SA and McCready DR. Mammographic density and the risk of breast cancer recurrence after breast-conserving surgery. Cancer. 2009; 115:5780-5787.

5. Buist DS, Abraham LA, Barlow WE, Krishnaraj A, Holdridge RC, Sickles EA, Carney PA, Kerlikowske K and Geller BM. Diagnosis of second breast cancer events after initial diagnosis of early stage breast cancer. Breast Cancer Res Treat. 2010; 124:863-873.

6. Boyd NF, Dite GS, Stone J, Gunasekara A, English DR, McCredie MR, Giles GG, Tritchler D, Chiarelli A, Yaffe MJ and Hopper JL. Heritability of mammographic density, a risk factor for breast cancer. N Engl J Med. 2002; 347:886-894.

7. Ursin G, Lillie EO, Lee E, Cockburn M, Schork NJ, Cozen W, Parisky YR, Hamilton AS, Astrahan MA and Mack T. The relative importance of genetics and environment on mammographic density. Cancer Epidemiol Biomarkers Prev. 2009; 18:102-112.

8. Stevens KN, Lindstrom S, Scott CG, Thompson D, Sellers TA, Wang X, Wang A, Atkinson E, Rider DN, EckelPassow JE, Varghese JS, Audley T, Brown J, Leyland J, Luben RN, Warren RM, et al. Identification of a novel percent mammographic density locus at 12q24. Hum Mol Genet. 2012; 21:3299-3305.

9. Vachon CM, Scott CG, Fasching PA, Hall P, Tamimi RM, Li J, Stone J, Apicella C, Odefrey F, Gierach GL, Jud SM, Heusinger K, Beckmann MW, Pollan M, FernandezNavarro P, Gonzalez-Neira A, et al. Common breast cancer susceptibility variants in LSP1 and RAD51L1 are associated with mammographic density measures that predict breast cancer risk. Cancer Epidemiol Biomarkers Prev. 2012; 21:1156-1166.

10. Lindstrom S, Vachon CM, Li J, Varghese J, Thompson D, Warren R, Brown J, Leyland J, Audley T, Wareham NJ, Loos RJ, Paterson AD, Rommens J, Waggott D, Martin LJ, Scott CG, et al. Common variants in ZNF365 are associated with both mammographic density and breast cancer risk. Nat Genet. 2011; 43:185-187.

11. Lindstrom S, Thompson DJ, Paterson AD, Li J, Gierach GL, Scott C, Stone J, Douglas JA, dos-Santos-Silva I, Fernandez-Navarro P, Verghase J, Smith P, Brown J, Luben R, Wareham NJ, Loos RJ, et al. Genome-wide association study identifies multiple loci associated with both mammographic density and breast cancer risk. Nat Commun. 5:5303.

12. Keller BM, McCarthy AM, Chen J, Armstrong K, Conant EF, Domchek SM and Kontos D. Associations between breast density and a panel of single nucleotide polymorphisms linked to breast cancer risk: a cohort study with digital mammography. BMC Cancer. 2015; 15:143.

13. Brand JS, Li J, Humphreys K, Karlsson R, Eriksson M, Ivansson E, Hall P and Czene K. Identification of two novel mammographic density loci at 6Q25.1. Breast Cancer Res. 2015; 17:75.

14. Stone J, Thompson DJ, Dos Santos Silva I, Scott C, Tamimi RM, Lindstrom S, Kraft P, Hazra A, Li J, Eriksson L, Czene K, Hall P, Jensen M, Cunningham J, Olson JE, Purrington K, et al. Novel Associations between Common Breast Cancer Susceptibility Variants and Risk-Predicting Mammographic Density Measures. Cancer Res. 2015; 75:2457-2467.

15. Mitchell G, Antoniou AC, Warren R, Peock S, Brown J, Davies R, Mattison J, Cook M, Warsi I, Evans DG, Eccles D, Douglas F, Paterson J, Hodgson S, Izatt L, Cole T, et al. Mammographic density and breast cancer risk in BRCA1 and BRCA2 mutation carriers. Cancer Res. 2006; 66:18661872.

16. Gierach GL, Loud JT, Chow CK, Prindiville SA, EngWong J, Soballe PW, Giambartolomei C, Mai PL, Galbo CE, Nichols K, Calzone KA, Vachon C, Gail MH and Greene MH. Mammographic density does not differ 
between unaffected BRCA1/2 mutation carriers and women at low-to-average risk of breast cancer. Breast Cancer Res Treat. 2010; 123:245-255.

17. Pike MC, Krailo MD, Henderson BE, Casagrande JT and Hoel DG. 'Hormonal' risk factors, 'breast tissue age' and the age-incidence of breast cancer. Nature. 1983; 30:767770 .

18. Greendale GA, Reboussin BA, Slone S, Wasilauskas C, Pike MC and Ursin G. Postmenopausal hormone therapy and change in mammographic density. J Natl Cancer Inst. 2003; 95:30-37.

19. van Duijnhoven FJ, Peeters PH, Warren RM, Bingham SA, van Noord PA, Monninkhof EM, Grobbee DE and van Gils CH. Postmenopausal hormone therapy and changes in mammographic density. J Clin Oncol. 2007; 25:1323-1328.

20. Nguyen TL, Schmidt DF, Makalic E, Dite GS, Stone J, Apicella C, Bui M, MacInnis RJ, Odefrey F, Cawson J, Treloar SA, Southey MC, Giles GG and Hopper JL. Explaining variance in the cumulus measures that predict breast cancer risk: a twins and sisters study. Cancer Epidemiol Biomarkers Prev. 2013; 22(12):2395-2403.

21. NF Boyd HG, LJ Martin, L Sun, J Stone, E Fishell, RA Jong, G Hislop, A Chiarelli, S Minkin, MJ Yaffe. Mammographic density and the risk and detection fo breast cancer. New England Journal of Medicine. 2007; 356:227236.

22. Boyd NF, Martin L, Stone J, Little L, Minkin S and Yaffe M. A longitudinal study of the effects of menopause on mammographic features. Cancer, Epidemiology, Biomarkers and Prevention. 2002; 11(10 Pt 1):1048-1053.

23. Boyd NF, Martin LJ, Sun L, Guo H, Chiarelli A, Hislop G, Yaffe $\mathrm{M}$ and Minkin S. Body size, mammographic density, and breast cancer risk. Cancer Epidemiol Biomarkers Prev. 2006; 15:2086-2092.

24. Boyd NF, Lockwood GA, Byng JW, Little LE, Yaffe MJ and Tritchler DL. The relationship of anthropometric measures to radiological features of the breast in premenopausal women. Br J Cancer. 1998; 78:1233-1238.

25. Thomson CA, Arendell LA, Bruhn RL, Maskarinec G, Lopez AM, Wright NC, Moll CE, Aickin M and Chen Z. Pilot study of dietary influences on mammographic density in pre- and postmenopausal Hispanic and non-Hispanic white women. Menopause. 2007; 14:243-250.

26. Habel LA, Capra AM, Oestreicher N, Greendale GA, Cauley JA, Bromberger J, Crandall CJ, Gold EB, Modugno F, Salane M, Quesenberry C and Sternfeld B. Mammographic density in a multiethnic cohort. Menopause. 2007; 14:891-899.

27. Reeves KW, Stone RA, Modugno F, Ness RB, Vogel VG, Weissfeld JL, Habel LA, Sternfeld B and Cauley JA. Longitudinal association of anthropometry with mammographic breast density in the Study of Women's Health Across the Nation. Int J Cancer. 2009; 124:11691177.
28. Antoni S, Sasco AJ, dos Santos Silva I and McCormack $\mathrm{V}$. Is mammographic density differentially associated with breast cancer according to receptor status? A meta-analysis. Breast Cancer Res Treat. 2012; 137:337-347.

29. Cuzick J, Warwick J, Pinney E, Warren RM and Duffy SW. Tamoxifen and breast density in women at increased risk of breast cancer. J Natl Cancer Inst. 2004; 96:621-628.

30. Cuzick J, Warwick J, Pinney E, Duffy SW, Cawthorn S, Howell A, Forbes JF and Warren RM. Tamoxifen-induced reduction in mammographic density and breast cancer risk reduction: a nested case-control study. J Natl Cancer Inst. 2011; 103:744-752.

31. Li J, Humphreys K, Eriksson L, Edgren G, Czene K and Hall P. Mammographic density reduction is a prognostic marker of response to adjuvant tamoxifen therapy in postmenopausal patients with breast cancer. J Clin Oncol. 2013; 31:2249-2256.

32. Li J, Czene K, Brauch H, Schroth W, Saladores P, Li Y, Humphreys K and Hall P. Association of CYP2D6 metabolizer status with mammographic density change in response to tamoxifen treatment. Breast Cancer Res. 2013; 15:R93.

33. Hattar R, Maller O, McDaniel S, Hansen KC, Hedman KJ, Lyons TR, Lucia S, Wilson RS, Jr. and Schedin P. Tamoxifen induces pleiotrophic changes in mammary stroma resulting in extracellular matrix that suppresses transformed phenotypes. Breast Cancer Res. 2009; 11:R5.

34. Chew GL, Huo CW, Huang D, Blick T, Hill P, Cawson J, Frazer H, Southey MC, Hopper JL, Britt K, Henderson MA, Haviv I and Thompson EW. Effects of Tamoxifen and oestrogen on histology and radiographic density in high and low mammographic density human breast tissues maintained in murine tissue engineering chambers. Breast Cancer Res Treat. 2014; 148:303-314.

35. Li T, Sun L, Miller N, Nicklee T, Woo J, Hulse-Smith L, Tsao MS, Khokha R, Martin L and Boyd N. The association of measured breast tissue characteristics with mammographic density and other risk factors for breast cancer. Cancer Epidemiol Biomarkers Prev. 2005; 14:343349.

36. Alowami S, Troup S, Al-Haddad S, Kirkpatrick I and Watson PH. Mammographic density is related to stroma and stromal proteoglycan expression. Breast Cancer Research. 2003; 5:R129-135.

37. Lin SJ, Cawson J, Hill P, Haviv I, Jenkins M, Hopper JL, Southey MC, Campbell IG and Thompson EW. Imageguided sampling reveals increased stroma and lower glandular complexity in mammographically dense breast tissue. Breast Cancer Res Treat. 2011; 128:505-516.

38. Warren R and Lakhani SR. Can the stroma provide the clue to the cellular basis for mammographic density? Breast Cancer Research. 2003; 5:225-227.

39. Sun X, Gierach GL, Sandhu R, Williams T, Midkiff BR, Lissowska J, Wesolowska E, Boyd NF, Johnson NB, 
Figueroa JD, Sherman ME and Troester MA. Relationship of mammographic density and gene expression: analysis of normal breast tissue surrounding breast cancer. Clin Cancer Res. 2013; 19:4972-4982.

40. Pang JM, Byrne DJ, Takano EA, Jene N, Petelin L, McKinley J, Poliness C, Saunders C, Taylor D, Mitchell $G$ and Fox SB. Breast Tissue Composition and Immunophenotype and Its Relationship with Mammographic Density in Women at High Risk of Breast Cancer. PLoS One. 2015; 10:e0128861.

41. Huo CW, Chew G, Hill P, Huang D, Ingman W, Hodson L, Brown KA, Magenau A, Allam AH, McGhee E, Timpson P, Henderson MA, Thompson EW and Britt K. High mammographic density is associated with an increase in stromal collagen and immune cells within the mammary epithelium. Breast Cancer Res. 2015; 17:79.

42. Vachon CM, Sasano H, Ghosh K, Brandt KR, Watson DA, Reynolds C, Lingle WL, Goss PE, Li R, Aiyar SE, Scott CG, Pankratz VS, Santen RJ and Ingle JN. Aromatase immunoreactivity is increased in mammographically dense regions of the breast. Breast Cancer Res Treat. 2011; 125:243-252.

43. McCormack VA, Dowsett M, Folkerd E, Johnson N, Palles C, Coupland B, Holly JM, Vinnicombe SJ, Perry NM and dos Santos Silva I. Sex steroids, growth factors and mammographic density: a cross-sectional study of UK postmenopausal Caucasian and Afro-Caribbean women. Breast Cancer Res. 2009; 11:R38.

44. Boyd NF, Stone J, Martin LJ, Jong R, Fishell E, Yaffe $\mathrm{M}$, Hammond $\mathrm{G}$ and Minkin $\mathrm{S}$. The association of breast mitogens with mammographic densities. Br J Cancer. 2002; 87:876-882.

45. Byrne C, Colditz GA, Willett WC, Speizer FE, Pollak M and Hankinson SE. Plasma insulin-like growth factor (IGF) I, IGF-binding protein 3, and mammographic density. Cancer Res. 2000; 60:3744-3748.

46. Guo YP, Martin LJ, Hanna W, Banerjee D, Miller N, Fishell E, Khokha R and Boyd NF. Growth factors and stromal matrix proteins associated with mammographic densities. Cancer Epidemiol Biomarkers Prev. 2001; 10:243-248.

47. Diorio C, Brisson J, Berube S and Pollak M. Genetic polymorphisms involved in insulin-like growth factor (IGF) pathway in relation to mammographic breast density and IGF levels. Cancer Epidemiol Biomarkers Prev. 2008; 17(4):880-888.

48. Allen M and Louise Jones J. Jekyll and Hyde: the role of the microenvironment on the progression of cancer. J Pathol. 2010; 223:162-176.

49. Pickup MW, Mouw JK and Weaver VM. The extracellular matrix modulates the hallmarks of cancer. EMBO Rep. 2014; 15:1243-1253.

50. Bergamaschi A, Tagliabue E, Sorlie T, Naume B, Triulzi T, Orlandi R, Russnes HG, Nesland JM, Tammi R, Auvinen P, Kosma VM, Menard S and Borresen-Dale AL. Extracellular matrix signature identifies breast cancer subgroups with different clinical outcome. J Pathol. 2008; 214:357-367.

51. Farmer P, Bonnefoi H, Anderle P, Cameron D, Wirapati P, Becette V, Andre S, Piccart M, Campone M, Brain E, Macgrogan G, Petit T, Jassem J, Bibeau F, Blot E, Bogaerts $\mathrm{J}$, et al. A stroma-related gene signature predicts resistance to neoadjuvant chemotherapy in breast cancer. Nat Med. 2009; 15:68-74.

52. Helleman J, Jansen MP, Ruigrok-Ritstier K, van Staveren IL, Look MP, Meijer-van Gelder ME, Sieuwerts AM, Klijn JG, Sleijfer S, Foekens JA and Berns EM. Association of an extracellular matrix gene cluster with breast cancer prognosis and endocrine therapy response. Clin Cancer Res. 2008; 14:5555-5564.

53. Bremnes Y, Ursin G, Bjurstam N, Rinaldi S, Kaaks R and Gram IT. Endogenous sex hormones, prolactin and mammographic density in postmenopausal Norwegian women. Int J Cancer. 2007; 121:2506-2511.

54. Ghosh S, Kang T, Wang H, Hu Y and Li R. Mechanical phenotype is important for stromal aromatase expression. Steroids. 2011; 76:797-801.

55. Conklin MW and Keely PJ. Why the stroma matters in breast cancer: insights into breast cancer patient outcomes through the examination of stromal biomarkers. Cell Adh Migr. 2012; 6:249-260.

56. Provenzano PP, Inman DR, Eliceiri KW, Knittel JG, Yan L, Rueden CT, White JG and Keely PJ. Collagen density promotes mammary tumor initiation and progression. BMC Med. 2008; 6:11.

57. Provenzano PP, Inman DR, Eliceiri KW and Keely PJ. Matrix density-induced mechanoregulation of breast cell phenotype, signaling and gene expression through a FAKERK linkage. Oncogene. 2009; 28:4326-4343.

58. Raviraj V, Fok S, Zhao J, Chien HY, Lyons JG, Thompson EW and Soon L. Regulation of ROCK1 via Notch1 during breast cancer cell migration into dense matrices. BMC Cell Biol. 2012; 13:12.

59. Provenzano PP, Eliceiri KW, Campbell JM, Inman DR, White JG and Keely PJ. Collagen reorganization at the tumor-stromal interface facilitates local invasion. BMC Med. 2006; 4:38.

60. Conklin MW, Eickhoff JC, Riching KM, Pehlke CA, Eliceiri KW, Provenzano PP, Friedl A and Keely PJ. Aligned collagen is a prognostic signature for survival in human breast carcinoma. Am J Pathol. 178:1221-1232.

61. Levental KR, Yu H, Kass L, Lakins JN, Egeblad M, Erler JT, Fong SF, Csiszar K, Giaccia A, Weninger W, Yamauchi M, Gasser DL and Weaver VM. Matrix crosslinking forces tumor progression by enhancing integrin signaling. Cell. 2009; 139:891-906.

62. Webster MA, Hutchinson JN, Rauh MJ, Muthuswamy SK, Anton M, Tortorice CG, Cardiff RD, Graham FL, Hassell JA and Muller WJ. Requirement for both Shc and phosphatidylinositol 3' kinase signaling pathways in 
polyomavirus middle T-mediated mammary tumorigenesis. Mol Cell Biol. 1998; 18:2344-2359.

63. Erler JT and Weaver VM. Three-dimensional context regulation of metastasis. Clin Exp Metastasis. 2009; 26:3549.

64. Barker HE, Cox TR and Erler JT. The rationale for targeting the LOX family in cancer. Nat Rev Cancer. 2012; 12:540552.

65. Erler JT, Bennewith KL, Nicolau M, Dornhofer N, Kong C, Le QT, Chi JT, Jeffrey SS and Giaccia AJ. Lysyl oxidase is essential for hypoxia-induced metastasis. Nature. 2006; 440:1222-1226.

66. Rubashkin MG, Cassereau L, Bainer R, DuFort CC, Yui Y, Ou G, Paszek MJ, Davidson MW, Chen YY and Weaver VM. Force engages vinculin and promotes tumor progression by enhancing PI3K activation of phosphatidylinositol (3,4,5)-triphosphate. Cancer Res. 2014; 74:4597-4611.

67. Mouw JK, Yui Y, Damiano L, Bainer RO, Lakins JN, Acerbi I, Ou G, Wijekoon AC, Levental KR, Gilbert PM, Hwang ES, Chen YY and Weaver VM. Tissue mechanics modulate microRNA-dependent PTEN expression to regulate malignant progression. Nat Med. 2014; 20:360367.

68. DeFilippis RA, Chang H, Dumont N, Rabban JT, Chen YY, Fontenay GV, Berman HK, Gauthier ML, Zhao J, Hu D, Marx JJ, Tjoe JA, Ziv E, Febbraio M, Kerlikowske K, Parvin B, et al. CD36 repression activates a multicellular stromal program shared by high mammographic density and tumor tissues. Cancer Discov. 2:826-839.

69. DeFilippis RA, Fordyce C, Patten K, Chang H, Zhao J, Fontenay GV, Kerlikowske K, Parvin B and Tlsty TD. Stress signaling from human mammary epithelial cells contributes to phenotypes of mammographic density. Cancer Res. 2014; 74:5032-5044.

70. Lisanti MP, Tsirigos A, Pavlides S, Reeves KJ, PeirisPages M, Chadwick AL, Sanchez-Alvarez R, Lamb R, Howell A, Martinez-Outschoorn UE and Sotgia F. JNK1 stress signaling is hyper-activated in high breast density and the tumor stroma: connecting fibrosis, inflammation, and stemness for cancer prevention. Cell Cycle. 2014; 13:580599.

71. Martin LJ and Boyd NF. Mammographic density. Potential mechanisms of breast cancer risk associated with mammographic density: hypotheses based on epidemiological evidence. Breast Cancer Res. 2008; 10:201.

72. Yang WT, Lewis MT, Hess K, Wong H, Tsimelzon A, Karadag N, Cairo M, Wei C, Meric-Bernstam F, Brown P, Arun B, Hortobagyi GN, Sahin A and Chang JC. Decreased TGFbeta signaling and increased COX2 expression in high risk women with increased mammographic breast density. Breast Cancer Res Treat. 2009; 119:305-314.

73. Studer RK and Chu CR. p38 MAPK and COX2 inhibition modulate human chondrocyte response to TGF-beta. J
Orthop Res. 2005; 23:454-461.

74. Aiello EJ, Buist DS, White E and Porter PL. Association between mammographic breast density and breast cancer tumor characteristics. Cancer Epidemiol Biomarkers Prev. 2005; 14:662-668.

75. Khan QJ, Kimler BF, O'Dea AP, Zalles CM, Sharma P and Fabian CJ. Mammographic density does not correlate with Ki-67 expression or cytomorphology in benign breast cells obtained by random periareolar fine needle aspiration from women at high risk for breast cancer. Breast Cancer Res. 2007; 9:R35.

76. Chew GL, Huo CW, Huang D, Hill P, Cawson J, Frazer H, Hopper JL, Haviv I, Henderson MA, Britt K and Thompson EW. Increased COX-2 expression in epithelial and stromal cells of high mammographic density tissues and in a xenograft model of mammographic density. Breast Cancer Res Treat. 2015.

77. Chen J, Pee D, Ayyagari R, Graubard B, Schairer C, Byrne $\mathrm{C}$, Benichou J and Gail MH. Projecting absolute invasive breast cancer risk in white women with a model that includes mammographic density. J Natl Cancer Inst. 2006; 98:1215-1226.

78. Tice JA, Cummings SR, Smith-Bindman R, Ichikawa L, Barlow WE and Kerlikowske K. Using clinical factors and mammographic breast density to estimate breast cancer risk: development and validation of a new predictive model. Ann Intern Med. 2008; 148:337-347.

79. Tice JA, Cummings SR, Ziv E and Kerlikowske K. Mammographic breast density and the Gail model for breast cancer risk prediction in a screening population. Breast Cancer Res Treat. 2005; 94:115-122.

80. Barlow WE, White E, Ballard-Barbash R, Vacek PM, Titus-Ernstoff L, Carney PA, Tice JA, Buist DS, Geller BM, Rosenberg R, Yankaskas BC and Kerlikowske K. Prospective breast cancer risk prediction model for women undergoing screening mammography. J Natl Cancer Inst. 2006; 98:1204-1214.

81. Schousboe JT, Kerlikowske K, Loh A and Cummings SR. Personalizing mammography by breast density and other risk factors for breast cancer: analysis of health benefits and cost-effectiveness. Ann Intern Med. 2011; 155:10-20.

82. Boyd NF, Martin LJ, Yaffe MJ and Minkin S. Mammographic density and breast cancer risk: current understanding and future prospects. Breast Cancer Res. 2011; 13:223.

83. Zhou J, Mauerer K, Farina L and Gribben JG. The role of the tumor microenvironment in hematological malignancies and implication for therapy. Front Biosci. 2005; 10:15811596.

84. Fang $H$ and Declerck YA. Targeting the tumor microenvironment: from understanding pathways to effective clinical trials. Cancer Res. 2013; 73:4965-4977.

85. Rini BI and Atkins MB. Resistance to targeted therapy in renal-cell carcinoma. Lancet Oncol. 2009; 10:992-1000. 
86. Lieu C, Heymach J, Overman M, Tran H and Kopetz S. Beyond VEGF: inhibition of the fibroblast growth factor pathway and antiangiogenesis. Clin Cancer Res. 2011; 17:6130-6139.

87. Xiong HQ, Herbst R, Faria SC, Scholz C, Davis D, Jackson EF, Madden T, McConkey D, Hicks M, Hess K, Charnsangavej CA and Abbruzzese JL. A phase I surrogate endpoint study of SU6668 in patients with solid tumors. Invest New Drugs. 2004; 22:459-466.

88. Rossi JF, Négrier S, James ND, Kocak I, Hawkins R, Davis H, Prabhakar U, Qin X, Mulders P and Berns B. A phase I/II study of siltuximab (CNTO 328), an anti-interleukin-6 monoclonal antibody, in metastatic renal cell cancer. Br J Cancer. 2010; 103:1154-1162.

89. Zollo M, Di Dato V, Spano D, De Martino D, Liguori L, Marino N, Vastolo V, Navas L, Garrone B, Mangano G, Biondi G and Guglielmotti A. Targeting monocyte chemotactic protein-1 synthesis with bindarit induces tumor regression in prostate and breast cancer animal models. Clin Exp Metastasis. 2012; 29:585-601.

90. O’Day S, Pavlick A, Loquai C, Lawson D, Gutzmer R, Richards J, Schadendorf D, Thompson JA, Gonzalez R, Trefzer U, Mohr P, Ottensmeier C, Chao D, Zhong B, de Boer CJ, Uhlar C, et al. A randomised, phase II study of intetumumab, an anti- $\alpha \mathrm{v}$-integrin $\mathrm{mAb}$, alone and with dacarbazine in stage IV melanoma. Br J Cancer. 2011; 105:346-352.
91. Hersey P, Sosman J, O'Day S, Richards J, Bedikian A, Gonzalez R, Sharfman W, Weber R, Logan T, Buzoianu M, Hammershaimb L, Kirkwood JM and Group EMS. A randomized phase 2 study of etaracizumab, a monoclonal antibody against integrin alpha(v)beta(3), + or - dacarbazine in patients with stage IV metastatic melanoma. Cancer. 2010; 116:1526-1534.

92. Ostermann E, Garin-Chesa P, Heider KH, Kalat M, Lamche H, Puri C, Kerjaschki D, Rettig WJ and Adolf GR. Effective immunoconjugate therapy in cancer models targeting a serine protease of tumor fibroblasts. Clin Cancer Res. 2008; 14:4584-4592.

93. LeBeau AM, Brennen WN, Aggarwal S and Denmeade SR. Targeting the cancer stroma with a fibroblast activation protein-activated promelittin protoxin. Mol Cancer Ther. 2009; 8:1378-1386.

94. Loeffler M, Krüger JA, Niethammer AG and Reisfeld RA. Targeting tumor-associated fibroblasts improves cancer chemotherapy by increasing intratumoral drug uptake. J Clin Invest. 2006; 116:1955-1962. 